\title{
Dynamic regulation of mitochondrial-endoplasmic reticulum crosstalk during stem cell homeostasis and aging
}

\author{
Weiping Lin $\mathbb{D}^{1,2^{凶}}$, Shuxun Chen ${ }^{3}$, Yan Wang ${ }^{2}$, Ming Wang ${ }^{2}$, Wayne Yuk-Wai Lee ${ }^{2,4,5}$, Xiaohua Jiang (DD $^{5,6}$ and Gang Li $i^{2,5,6 \bowtie}$
}

(c) The Author(s) 2021

Cellular therapy exerts profound therapeutic potential for curing a broad spectrum of diseases. Adult stem cells reside within a specified dynamic niche in vivo, which is essential for continuous tissue homeostatic maintenance through balancing self-renewal with lineage selection. Meanwhile, adult stem cells may be multipotent or unipotent, and are present in both quiescent and actively dividing states in vivo of the mammalians, which may switch to each other state in response to biophysical cues through mitochondria-mediated mechanisms, such as alterations in mitochondrial respiration and metabolism. In general, stem cells facilitate tissue repair after tissue-specific homing through various mechanisms, including immunomodulation of local microenvironment, differentiation into functional cells, cell "empowerment" via paracrine secretion, immunoregulation, and intercellular mitochondrial transfer. Interestingly, cell-source-specific features have been reported between different tissue-derived adult stem cells with distinct functional properties due to the different microenvironments in vivo, as well as differential functional properties in different tissue-derived stem cell-derived extracellular vehicles, mitochondrial metabolism, and mitochondrial transfer capacity. Here, we summarized the current understanding on roles of mitochondrial dynamics during stem cell homeostasis and aging, and lineage-specific differentiation. Also, we proposed potential unique mitochondrial molecular signature features between different source-derived stem cells and potential associations between stem cell aging and mitochondria-endoplasmic reticulum (ER) communication, as well as potential novel strategies for anti-aging intervention and healthy aging.

Cell Death and Disease (2021)12:794; https://doi.org/10.1038/s41419-021-03912-4

\section{FACTS}

- Stem cell niche is essential for cell-fate decisions via regulation of stem cell homeostasis and mitochondrial dynamics of fusion and fission through balancing self-renewal and lineagespecific differentiation, as well as stem cell quiescence and activation.

- Circulating cell-free mitochondria exist within the peripheral blood, which may be involved in various pathophysiological processes.

- Mitochondria are highly dynamic organelles that change their morphology in response to cellular signals and differentiation states.

- Mitochondria-endoplasmic reticulum crosstalk is implicated in aging progression.

- Asymmetrically sort and distribution of aged and young mitochondria are critically involved in stemness regulation of stem cells.

\section{OPEN QUESTIONS}

- Is mitochondrial functional decline involved in aging progression of stem cells through age-dependent subcellular localization and redistribution of the mitochondria, thereby causing loss of stem cell properties?

- Are mitochondrial connections and transfer implicated in cellbased therapies via sharing and receiving of energetic and young mitochondria of cells of damaged tissues from functional stem cells?

- Is the coupling of endoplasmic reticulum (ER) stress and cell differentiation associated with the interplay between mitochondrial-ER crosstalk?

- Is it possible to alleviate stem cell aging or achieve rejuvenation of aging stem cells through switching prolonged or excessive endoplasmic reticulum (ER) stress to adaptive ER stress via regulation of mitochondrial function and stem cell niche?

\footnotetext{
${ }^{1}$ Centre for Regenerative Medicine and Health, Hong Kong Institute of Science \& Innovation, Chinese Academy of Sciences, Hong Kong SAR, China. ${ }^{2}$ Stem Cells and Regenerative Medicine Laboratory, Department of Orthopaedics and Traumatology, Li Ka Shing Institute of Health Sciences, Prince of Wales Hospital, The Chinese University of Hong Kong, Hong Kong SAR, China. ${ }^{3}$ Department of Biomedical Engineering, City University of Hong Kong, Hong Kong SAR, China. ${ }^{4}$ SH Ho Scoliosis Research Laboratory, Joint Scoliosis Research Center of the Chinese University of Hong Kong and Nanjing University, Department of Orthopaedics and Traumatology, The Chinese University of Hong Kong, Hong Kong SAR, China. ${ }^{5}$ Shenzhen Research Institute, The Chinese University of Hong Kong, Shenzhen, China. ${ }^{6}$ Faculty of Medicine, MOE Key Laboratory for Regenerative Medicine,

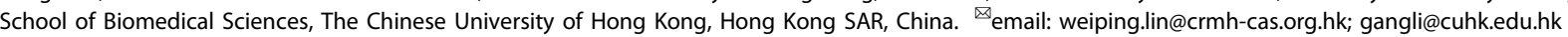
Edited by P. Pinton
} 


\section{INTRODUCTION}

Stem cell-based therapies exert profound therapeutic potential for curing a broad spectrum of diseases [1, 2]. Adult stem cells reside in a specified dynamic niche that is essential for continuous tissue homeostatic maintenance through balancing self-renewal with lineage selection [3, 4]. Meanwhile, adult stem cells may be multipotent or unipotent, and are present in both quiescent and actively dividing states in vivo of the mammalians, which may switch to each other state in response to various intrinsic or extrinsic signals through mitochondria-mediated mechanisms, such as alterations in mitochondrial respiration and metabolism [4-9]. In addition, the co-incidence of endoplasmic reticulum (ER) and mitochondria, and their dynamic interconnections and crosstalk are involved in a series of cellular processes, including mitochondrial homeostasis in fusion and fission, autophagy, and inflammasome formation [10, 11].

Emerging novel techniques during recent years, such as singlecell transcriptomics for analysis of spatial and temporal turnover of certain cellular processes, may enable advancing our understanding of dynamic gene regulation in stem cell maintenance within stem cell niche, stem cell activation and mobilization, lineage specification, tissue-specific molecular phenotypes in adult stem cells, identification of major cell types and their localization, as well as cellular and spatial sources of key growth factors and cytokines [12-18].

\section{Diversity and heterogeneity of mitochondria}

Mitochondria are complex organelles existing in a network undergoing continuous morphological dynamic changes through fission and fusion, which is crucial for the maintenance of pluripotency and differentiation capacity of stem cells [19-24]. Mitochondria usually undergo continuous morphologic dynamic changes through fission and fusion events controlled by the large GTPases Drp1, Mfn1, Mfn2, and Opa1 (fusion), which are important for mitochondrial function, and their imbalance would cause cell dysfunction and various diseases [25-28]. Metabolic changes are essential for cell-lineage commitment during mesenchymal stem cell differentiation, accompanied with alterations in mitochondrial morphology and dynamics [21, 22, 29]. Distinct morphological characteristics of mesenchymal stem cells mitochondria occur during different lineage-specification state (Fig. 1).

In general, stem cells facilitate tissue repair after tissue-specific homing through various mechanisms, such as immunomodulation of local microenvironment, differentiation into functional cells [30, 31], cell "empowerment" via paracrine secretion [32-34], immunomodulation $[35,36]$, and intercellular mitochondrial transfer [37-40]. Recent studies have demonstrated intercellular mitochondrial transfer within osteocyte-dendritic network [41]. Intriguingly, potential mitochondrial connections and communications were also observed between co-cultured mature chondrocytes and stem cells ex vivo (Fig. 2A). Meanwhile, cellsource-specific features have been reported between different tissue-derived adult stem cells with distinct functional properties $[5,42]$, as well as differential functional properties in different tissue-derived stem cell-derived extracellular vehicles [43, 44], mitochondrial metabolism [45], and mitochondrial transfer capacity [46]. Strikingly, recent studies have reported the presence of circulating cell-free mitochondria within the peripheral blood, suggesting the diversity of existing forms of mitochondria $[47,48]$. Therefore, it is highly possible that distinct mitochondrial gene expression patterns may exist between different tissue-derived stem cells, owing to the heterogeneity of stem cells and diverse populations of mitochondrial DNA (mt-DNA) [48-55]. Simultaneously, visualization of replicating mt-DNA nucleoids has suggested the physical linkage between the ER and mitochondria (Fig. 2B) [56-58]. Therefore, manipulation of mt-DNA within cells may represent a powerful approach for the development of therapeutic interventions to treat mitochondrial diseases.
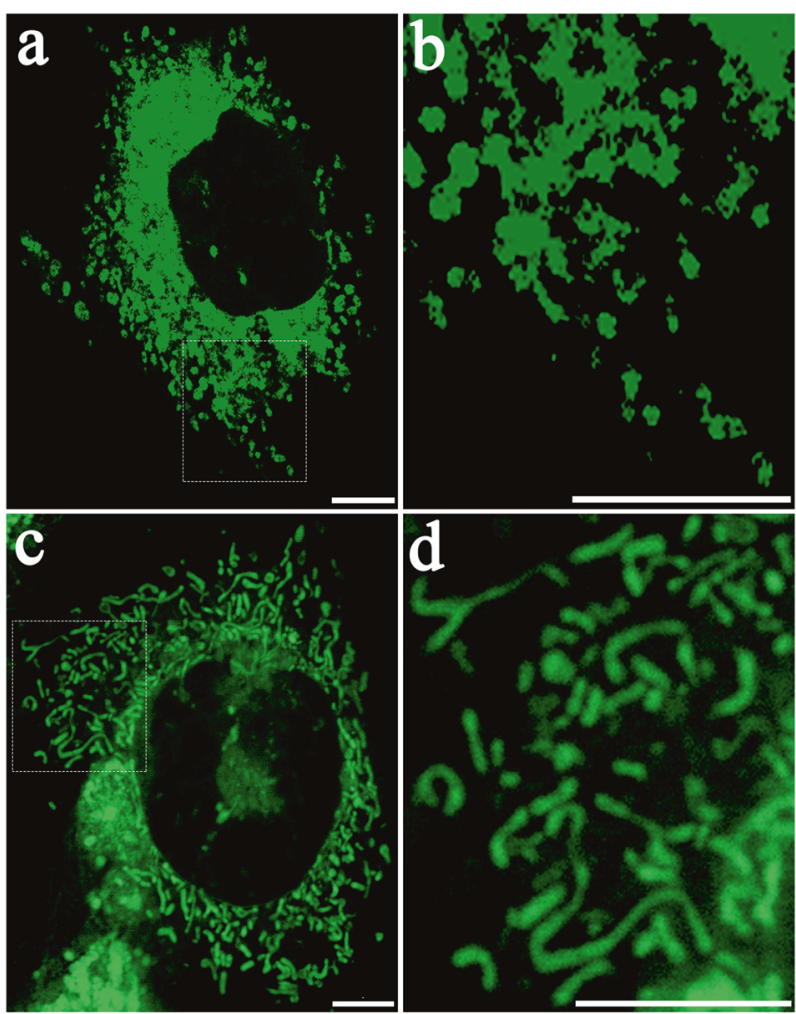

Fig. 1 Representative images of mitochondrial morphology. Observation of mitochondria of murine peripheral blood-derived mesenchymal stem cells (mPB-MSCs) under confocal microscope through Mito-Tracker Green staining. a, b Representative images of mitochondria of undifferentiated mPB-MSCs. c, d Representative images of mitochondria during osteogenic differentiation. Scale bar: $10 \mu \mathrm{m}$.

\section{Mitochondrial metabolic regulation on stem cell fates}

It is generally believed that stem cells fuel tissue development and tissue repair, and these activities are controlled by the local stem cell microenvironment or niche. Highly heterogeneous populations of resident stem/progenitor cells have been demonstrated residing within adult organs and tissues [55, 59-62]. An appropriate balance between self-renewal and differentiation is essential for stem cell function during both development and tissue homeostasis throughout life [63]. At steady state, adult stem cells are quiescent cells within niche. Both cell-intrinsic and -extrinsic signaling networks, such as mitochondrial dynamicassociated signaling, have been reported to fine-tune the selfrenewal and differentiation of stem cells, and are involved in tissue homeostasis and tissue repair $[64,65]$.

Notably, mitochondrial plasticity, such as mitochondrial metabolism and mitochondrial respiratory chain, is vital for cell-fate decisions and function of stem cells [66-69]. The metabolic switch of mitochondria is required for stem cell activation and cell cycle activity [70]. Meanwhile, accumulating evidence has suggested a causative association between mitochondrial dysfunction and major phenotypes associated with aging. The self-renewal of tissues and organs in aging organisms requires stem cells, which have the unusual ability to divide asymmetrically into one daughter cell that retains stem cell properties and another that differentiates into a particular tissue type. Further, mitochondria have been reported to distribute passively during mitosis upon their release from microtubules [71]. Importantly, subcellular localization and distribution of young and old mitochondria determine stemness properties in the progeny stem cells during asymmetric cell divisions. Subsequently, the daughter cells that 
A a

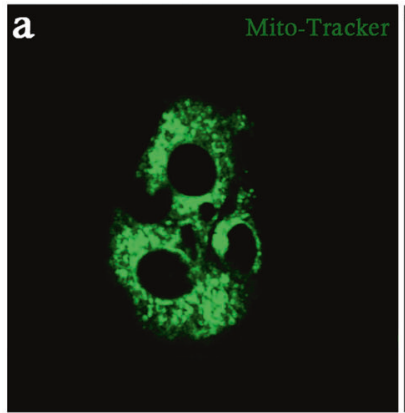

B

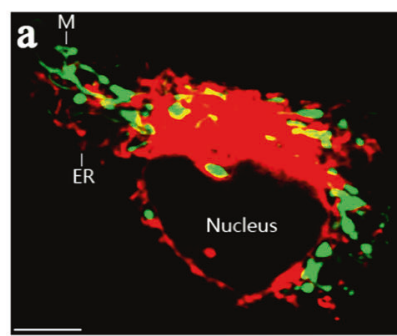

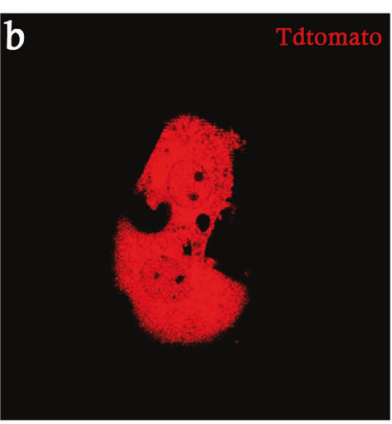
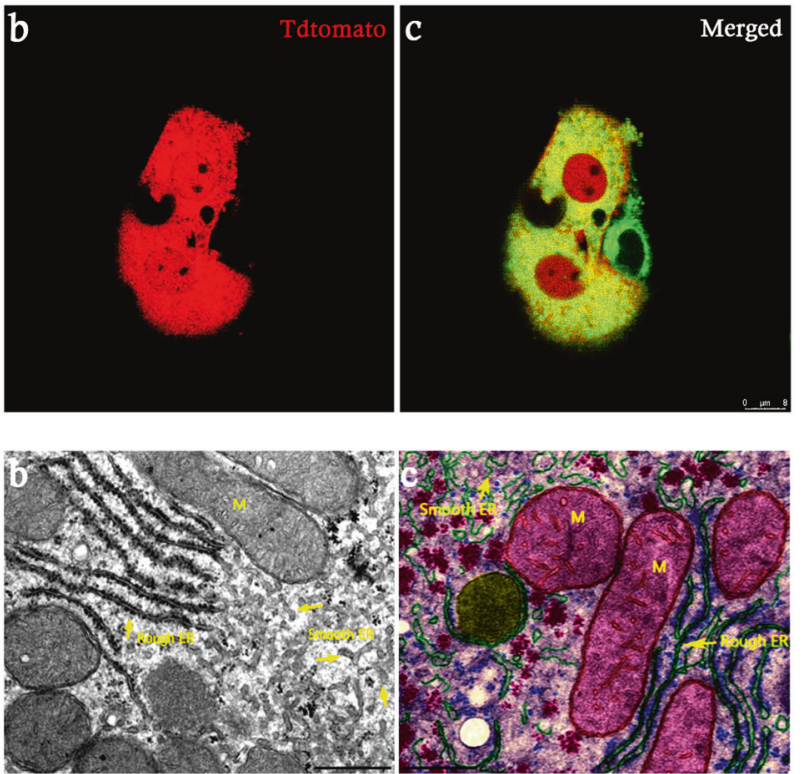

Fig. 2 Endoplasmic reticulum-mitochondrial localization. A Representative live mitochondrial images of tdTomato-labeled joint progenitor cells co-cultured with mature chondrocytes through Mito-Tracker Green staining under confocal microscope. a Representative live-cell imaging of mitochondria through Mito-Tracker Green staining; $\mathbf{b}$ representative live-cell imaging of tdTomato fluorescence; $\mathbf{c}$ merged images. Scale bar: $8 \mu \mathrm{m}$. B Structural features of mitochondria (M) and endoplasmic reticulum (ER) within cells. a Representative immunocytochemical images of M (green) and ER (red); scale bar: $10 \mu \mathrm{m}$. b Representative electron micrographs of M and ER; scale bar: $500 \mathrm{~nm}$. c Representative images of ultrastructure of $\mathrm{M}$ and ER. Scale bar: $500 \mathrm{~nm}$ (adapted from netterimages.com and chegg.com).

retains a stem cell nature inherits young mitochondria, whereas older mitochondria are inherited by the more differentiated cells [72]. Accumulation of aged mitochondria would lead to cell aging and cellular functional decline [70, 73]. Mohrin et al. [74] further elucidated a regulatory branch of mitochondrial unfolded protein response $\left(U P R^{\mathrm{mt}}\right)$ that is coupled to cellular energy metabolism and proliferation in stem cells. Mitochondrial protein-folding stress triggered a metabolic checkpoint regulating cell cycle, whereas deregulation of this pathway interfered with stem cell quiescence and compromised regenerative potential [74]. Therefore, mitochondrial function may represent an important determinant of the regenerative potential of stem cells.

Stem cells possess multi-differentiation potential into various cell types, making them medically relevant for the treatment of a variety of diseases and injuries. However, there remains a major hurdle of stem cell therapy into the clinics, namely the limited efficiency to create fully functional and specialized terminally differentiated cells. Mitochondrial dynamics is crucial for cell-fate determination of stem cells $[75,76]$. Importantly, different cell states require specific metabolic demands to support specialized functions [77]. Thus, efficient mitochondrial oxidative metabolism and dynamics are required for efficient specific lineage commitment [21, 78-83].

Strikingly, recent studies report that chaperone-mediated autophagy and a related metabolite in embryonic stem cells, also known as the self-eating process, have emerged as promising novel therapeutics for regeneration of damaged tissues and organs [84]. Simultaneously, accumulating evidence has indicated tight associations between mitochondrial metabolism and stem cell differentiation $[85,86]$. Studies have demonstrated that mouse embryonic stem cells sorted for low- and high-resting mitochondrial membrane potential $\left(\Delta \Psi_{m L}\right.$ and $\left.\Delta \Psi_{m H}\right)$ are indistinguishable in terms of morphology and expression levels of pluripotency markers, whereas differing markedly in metabolic rates, suggesting that a coupling between intrinsic metabolic parameters and stem cell fate may provide clues for novel enrichment strategies and therapeutic approaches of stem cell therapy [87, 88]. Furthermore, a recent study demonstrated lactate mobilization

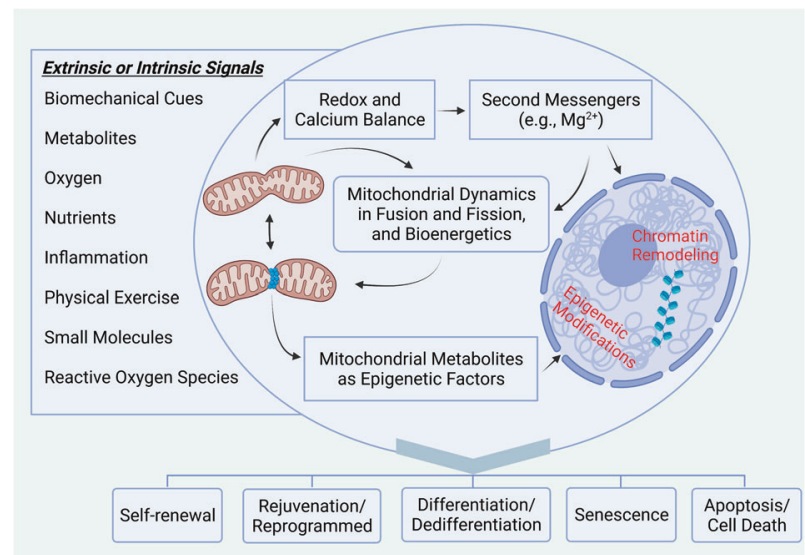

Fig. 3 Mitochondrial regulation of stem cell homeostasis and aging. Regulation of stem cell homeostasis in response to environmental cues and epigenetic factors. Upon exposure to various extrinsic or intrinsic signals, mitochondria respond through modulation of morphological network and bioenergetics, the redox and calcium balance, and epigenetic modifications and chromatin remodeling within stem cells. Cell-fate decisions occur following mitochondria-based cellular response, mainly including selfrenewal, rejuvenation/cell reprogrammed, differentiation/dedifferentiation, and senescence, cell death, or apoptosis [65, 134-142]. Created with BioRender.com.

of intracellular $\mathrm{Mg}^{2+}$, indicating potential links between mitochondrial $\mathrm{Mg}^{2+}$ transportation with major metabolic feedback circuits and mitochondrial bioenergetics (Fig. 3) [89].

\section{Correlations between mitochondrial functions and aging}

Adult stem cells are essential for tissue homeostasis and regeneration, yet are susceptible to senescence during aging [90-92], accompanied with aging microenvironments around adult stem cells $[93,94]$. The main hallmarks of aging in mammalian organisms 
include genomic instability, telomere attrition, epigenetic alterations, loss of proteostasis, deregulated nutrient sensing, mitochondrial dysfunction, cellular senescence, stem cell exhaustion, and altered intercellular communication [95]. The degeneration or dysfunction of aging tissues and organs is attributed to the deterioration of adult stem cells [95-97], which may result from disordered mitochondrial dynamics and declined mitochondrial functions [98-100]. Mitochondrial activity and metabolism are important determinants for specification of stem cell fate [87, 101].

Studies have demonstrated the importance of oxidized form of cellular nicotinamide adenine dinucleotide on mitochondrial activity as a pivotal switch to modulate muscle adult stem cell senescence [102, 103]. SIRT3, a mammalian sirtuin that regulates the global acetylation landscape of mitochondrial proteins and reduces oxidative stress, is suppressed during aging. In addition, the upregulation of SIRT3 in aged hematopoietic stem cells (HSCs) improved the regenerative capacity of HSCs [104]. Also, maintenance of self-renewal of a purified $\mathrm{Tie}^{2+} \mathrm{HSC}$ population relies on mitochondrial clearance [105]. Further studies have identified a regulatory branch of the UPR ${ }^{\mathrm{mt}}$, which mediated through the interplay between SIRT7 and NRF1, which is coupled to cellular energy metabolism and proliferation. Deregulation of a UPR ${ }^{\mathrm{mt}}$ mediated metabolic checkpoint as a reversible main factor for HSC aging [74]. Further, systemic chronic inflammation has been reported as an important feature of aging, which is critically implicated in the process of stem cell aging [106-108]. A recent study has uncovered mitochondrial stress-initiated aberrant activation of the NLRP3 inflammasome as a reversible driver of functional decline during HSC aging [109]. In the meanwhile, studies have documented the crucial roles of PTPMT1 (a PTEN-like mitochondrial phosphatase) in the metabolic regulation of selfrenewal and differentiation of HSCs [110].

\section{Mitochondria-ER crosstalk and aging}

Notably, surviving ER stress has been demonstrated coupling to altered chondrocyte differentiation and functioning, which facilitates survival and recovery through adaptive unfolded protein response (UPR) during pathophysiology of chondrodysplasia [111, 112]. Also, studies have suggested the intimate linkage between stress adaptation and aging process [113]. Stress responses and the aging

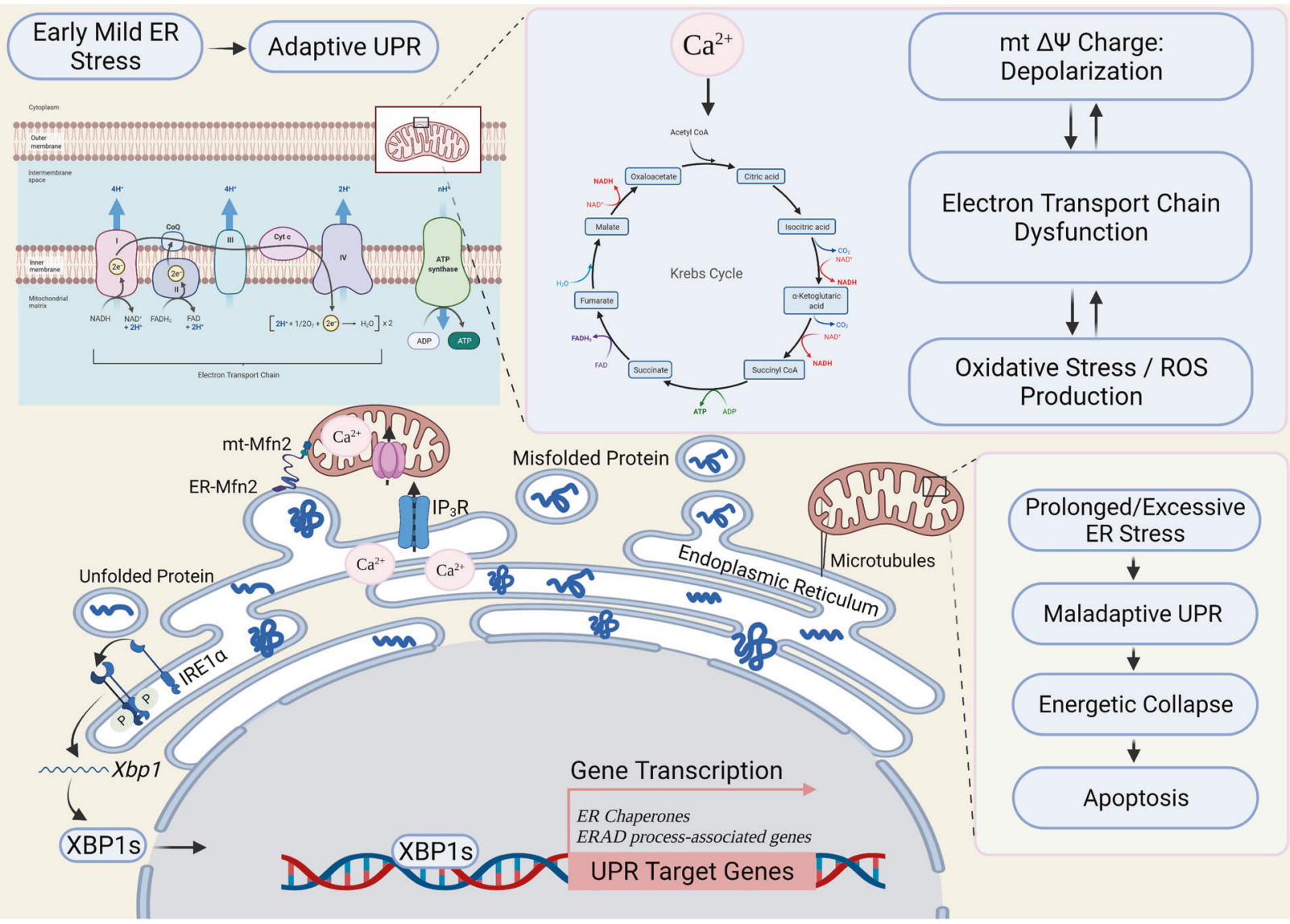

Fig. 4 Proposed working model of communication between mitochondria and endoplasmic reticulum stress. Endoplasmic reticulum (ER) stress triggers an increase in mitochondrial metabolism, which mainly relies on organelle coupling and $\mathrm{Ca}^{2+}$ transfer. The onset of ER stress is accompanied with redistribution of reticular and mitochondrial networks towards the perinuclear region and a microtubule-dependent increase in connection. Physical interaction is mainly achieved by anchoring proteins, such as Mitofusin 2 (Mfn2), which allows buffering of intracellular $\mathrm{Ca}^{2+}$ from ER to mitochondria through its endoplasmic reticulum-mitochondria tethering activity, enhancing mitochondrial bioenergetics and ATP production consequently. The unfolded protein response (UPR) is a cellular self-defense adaptive mechanism to restore ER homeostasis. Crosstalk between the UPR pathways could facilitate a coordinated response to conditions of ER stress. During early mild ER stress, activated IRE1 $\alpha$ then removes a 26-base intron from Xbp1 mRNA to generate a potent transcription factor XBP1s (Xbp1 spliced) that translocates into the nucleus and regulates a diverse array of genes, such as ER folding chaperones and ER-associated degradation (ERAD) process-associated genes. However, prolonged or excessive ER stress (e.g., induced by aging) would cause mitochondrial collapse and apoptotic cell death. ER: endoplasmic reticulum; UPR: unfolded protein response; ROS: reactive oxygen species; Mfn2: mitofusin 2; mt: mitochondrial; IRE1 $\alpha$ : inositol-requiring kinase $1 \alpha$ (ER stress sensor); XBP1: X-box-binding protein 1; XBP1s: spliced form of XBP1; Krebs cycle: also known as TCA cycle (tricarboxylic acid cycle); $I_{3} R$ : inositol trisphosphate receptor $\left(\mathrm{Ca}^{2+}\right.$ channels); mt $\Delta \Psi$ : mitochondrial membrane potential; ERAD: ER-associated degradation; ATP: adenosine 5'-triphosphate [74, 116117134, 142-145]. Created with BioRender.com. 
process may share common features and mechanisms initially arising from studies in model organisms [114, 115], where various molecular pathways have been demonstrated to implicate in the progression of aging process, including insulin/insulin-like growth factor, sirtuins, targets of rapamycin (TORs), and AMP-activated kinase. Thus, intrinsic induction of stress defense programs and the resulting adaptation may become a potential strategy to increase life expectancy [114]. Usually, mild ER stress activates the adaptive UPR on the one hand. Adaptive UPR is conducive to stress alleviation in response to cellular stress, which has recently been reported to preserve self-renewal of hematopoietic and preleukemic HSCs via inositol-requiring enzyme $1 \mathrm{a} / \mathrm{X}$-box-binding protein 1 signaling [116]. On the other hand, however, beyond a certain degree of ER damage, namely prolonged UPR response, would trigger apoptotic pathways (Fig. 4) [117-120]. Studies have suggested that depletion of the proteins involved in the regulation of mitochondrial-ER crosstalk, such as mammalian TOR, would lead to increased apoptosis, autophagy, and cellular dysfunction [121, 122]. In contrast, artificially increasing ER-mitochondria contacts in cells would restore cell viability [89, 119, 123, 124]. Studies have further identified critical roles of ER-mitochondria contacts in the biogenesis of mitochondrial-derived compartments [125-127], which may play essential roles in cellular adaptation to environmental stress conditions [127].

Importantly, aging is one of the main causing factors of the increased prolonged ER stress, accompanied with mitochondrial dysfunction consequently [128]. Thus, attenuation of ER stress is a potential approach for the improvement and restoration of mitochondrial function in aging organisms. In addition, studies have suggested the correlation between spatial re-organization of mitochondria and increased ATP levels, oxygen consumption, reductive power, and increased mitochondrial $\mathrm{Ca}^{2+}$ uptake $[129,130]$. However, uncoupling of the organelles or blocking $\mathrm{Ca}^{2+}$ transfer impaired the metabolic response, rendering cells more vulnerable to ER stress [129, 131]. Consequently, ER stress induces an early increase in mitochondrial metabolism that depends crucially upon organelle coupling and $\mathrm{Ca}^{2+}$ transfer, which, by enhancing cellular bioenergetics, establishes the metabolic basis for the adaptation to this response [129, 132]. As aging is one of the main factors causing increased ER stress and mitochondrial dysfunction, attenuation of ER stress is conducive to anti-aging [128]. Therefore, enhanced mitochondrial biogenesis has been reported associated with improved efficiency of the electron-transport chain, which may become a potential therapeutic anti-aging approach to block reactive oxygen species accumulation and promote cell survival through alleviation of ER stress [133].

\section{CONCLUSIONS}

All together, mitochondrial plasticity plays central roles in regulation of activity and functions of stem cells. Intrinsic and extrinsic signaling networks are responsible for dynamic regulation in mitochondrial function and adaptation to intrinsic and extrinsic signals for ultimate cell fate decisions. Interplay and crosstalk among aging microenvironments, ER stress, and interand intracellular mitochondrial dynamics are implicated in the progression of stem cell aging and functionally declined tissues and organs. Further extensive investigations on mitochondria-ER communication-associated stem cell aging, and changes of chromatin states and mitochondrial dynamics within the regenerative niche will not only boost the development of novel pharmaceutical targets for the cure of age-related disorders through targeting mitochondria-ER associated signaling pathways, but also provide novel insights into mitochondria-mediated stem cell activation during tissue regeneration. Identification of specific mitochondrial molecular signatures between different source-derived stem cells may advance our understanding of stem cell biology and shed light on novel strategies for healthy longevity and improved therapeutic outcomes of cellular therapy.

\section{REFERENCES}

1. Cable J, Fuchs E, Weissman I, Jasper H, Glass D, Rando T, et al. Adult stem cells and regenerative medicine-a symposium report. Ann. N. Y. Acad. Sci. 2020;1462:27.

2. Yamanaka S. Pluripotent stem cell-based cell therapy-promise and challenges. Cell Stem Cell. 2020;27:523-31.

3. Adam RC, Yang H, Rockowitz S, Larsen SB, Nikolova M, Oristian DS, et al. Pioneer factors govern super-enhancer dynamics in stem cell plasticity and lineage choice. Nature. 2015;521:366-70.

4. Li L, Clevers H. Coexistence of quiescent and active adult stem cells in mammals. Science. 2010;327:542-5.

5. Visvader JE, Clevers H. Tissue-specific designs of stem cell hierarchies. Nat. Cell Biol. 2016;18:349-55.

6. Bond AM, Ming GL, Song H. Adult mammalian neural stem cells and neurogenesis: five decades later. Cell Stem Cell. 2015;17:385-95.

7. Ransom RC, Carter AC, Salhotra A, Leavitt T, Marecic O, Murphy MP, et al. Mechanoresponsive stem cells acquire neural crest fate in jaw regeneration. Nature. 2018;563:514-21.

8. Zheng M, Kim SK, Joe Y, Back SH, Cho HR, Kim HP, et al. Sensing endoplasmic reticulum stress by protein kinase RNA-like endoplasmic reticulum kinase promotes adaptive mitochondrial DNA biogenesis and cell survival via heme oxygenase-1/carbon monoxide activity. FASEB J. 2012;26:2558-68.

9. Feng J, Lu S, Ding $Y$, Zheng $M$, Wang X. Homocysteine activates $T$ cells by enhancing endoplasmic reticulum-mitochondria coupling and increasing mitochondrial respiration. Protein Cell. 2016;7:391-402.

10. Marchi S, Patergnani S, Pinton $P$. The endoplasmic reticulum-mitochondria connection: one touch, multiple functions. Biochim Biophys. Acta. 2014;1837:461-9.

11. Genovese I, Vezzani B, Danese A, Modesti L, Vitto VAM, Corazzi V, et al. Mitochondria as the decision makers for cancer cell fate: from signaling pathways to therapeutic strategies. Cell Calcium. 2020;92:102308.

12. Cheng JB, Sedgewick AJ, Finnegan Al, Harirchian P, Lee J, Kwon S, et al. Transcriptional programming of normal and inflamed human epidermis at singlecell resolution. Cell Rep. 2018;25:871-83.

13. Feng C, Chan WCW, Lam Y, Wang X, Chen P, Niu B, et al. Lgr5 and Col22a1 mark progenitor cells in the lineage toward juvenile articular chondrocytes. Stem Cell Rep. 2019;13:713-29.

14. Pallafacchina G, Francois S, Regnault B, Czarny B, Dive V, Cumano A, et al. An adult tissue-specific stem cell in its niche: a gene profiling analysis of in vivo quiescent and activated muscle satellite cells. Stem Cell Res. 2010;4:77-91.

15. Hussenet T, Dembele D, Martinet N, Vignaud JM, du Manoir S. An adult tissuespecific stem cell molecular phenotype is activated in epithelial cancer stem cells and correlated to patient outcome. Cell Cycle. 2010;9:321-7.

16. Liang R, Ghaffari S. Mitochondria and FOXO3 in stem cell homeostasis, a window into hematopoietic stem cell fate determination. J. Bioenerg. Biomembr. 2017;49:343-6

17. Baccin C, Al-Sabah J, Velten L, Helbling PM, Grunschlager F, HernandezMalmierca $P$, et al. Combined single-cell and spatial transcriptomics reveal the molecular, cellular and spatial bone marrow niche organization. Nat. Cell Biol. 2020;22:38-48.

18. Finnegan A, Cho RJ, Luu A, Harirchian P, Lee J, Cheng JB, et al. Single-cell transcriptomics reveals spatial and temporal turnover of keratinocyte differentiation regulators. Front Genet. 2019;10:775.

19. Xu X, Duan S, Yi F, Ocampo A, Liu GH, Izpisua Belmonte JC. Mitochondrial regulation in pluripotent stem cells. Cell Metab. 2013;18:325-32.

20. Archer SL. Mitochondrial dynamics-mitochondrial fission and fusion in human diseases. N. Engl. J. Med. 2013;369:2236-51.

21. Forni MF, Peloggia J, Trudeau K, Shirihai O, Kowaltowski AJ. Murine mesenchymal stem cell commitment to differentiation is regulated by mitochondrial dynamics. Stem Cells. 2016;34:743-55.

22. Lin W, Xu L, Pan Q, Lin S, Feng L, Wang B, et al. Lgr5-overexpressing mesenchymal stem cells augment fracture healing through regulation of Wnt/ ERK signaling pathways and mitochondrial dynamics. FASEB J. 2019;33:8565-77.

23. Liu X, Weaver D, Shirihai O, Hajnoczky G. Mitochondrial 'kiss-and-run': interplay between mitochondrial motility and fusion-fission dynamics. EMBO J. 2009;28:3074-89.

24. Kasahara A, Cipolat S, Chen Y, Dorn GW, Scorrano L. Mitochondrial fusion directs cardiomyocyte differentiation via calcineurin and Notch signaling. Science. 2013;342:734-7.

25. Wang X, Su B, Siedlak SL, Moreira PI, Fujioka H, Wang Y, et al. Amyloid-beta overproduction causes abnormal mitochondrial dynamics via differential modulation of mitochondrial fission/fusion proteins. Proc. Natl Acad. Sci. USA. 2008;105:19318-23. 
26. Walter J, Bolognin S, Antony PMA, Nickels SL, Poovathingal SK, Salamanca L, et al. Neural stem cells of Parkinson's disease patients exhibit aberrant mitochondrial morphology and functionality. Stem Cell Rep. 2019;12:878-89.

27. Korobova F, Ramabhadran V, Higgs HN. An actin-dependent step in mitochondrial fission mediated by the ER-associated formin INF2. Science. 2013:339:464-7.

28. Angelova PR, Barilani M, Lovejoy $C$, Dossena $M$, Vigano $M$, Seresini $A$, et al. Mitochondrial dysfunction in Parkinsonian mesenchymal stem cells impairs differentiation. Redox Biol. 2018;14:474-84.

29. Guo J, Ren R, Yao X, Ye Y, Sun K, Lin J, et al. PKM2 suppresses osteogenesis and facilitates adipogenesis by regulating beta-catenin signaling and mitochondrial fusion and fission. Aging (Albany NY). 2020;12:3976-92.

30. Gojo S, Gojo N, Takeda Y, Mori T, Abe H, Kyo S, et al. In vivo cardiovasculogenesis by direct injection of isolated adult mesenchymal stem cells. Exp. Cell Res. 2003;288:51-9.

31. Su J, Guo L, Wu C. A mechanoresponsive PINCH-1-Notch2 interaction regulates smooth muscle differentiation of human placental mesenchymal stem cells. Stem Cells 2021;39:650-68.

32. Mirotsou M, Zhang Z, Deb A, Zhang L, Gnecchi M, Noiseux N, et al. Secreted frizzled related protein 2 (Sfrp2) is the key Akt-mesenchymal stem cell-released paracrine factor mediating myocardial survival and repair. Proc. Natl Acad. Sci. USA. 2007;104:1643-8.

33. Roefs MT, Sluijter JPG, Vader P. Extracellular vesicle-associated proteins in tissue repair. Trends Cell Biol. 2020;30:990-1013.

34. Hou Y, Lin W, Li Y, Sun Y, Liu Y, Chen C, et al. De-osteogenic-differentiated mesenchymal stem cells accelerate fracture healing by mir-92b. J. Orthop. Transl. 2021;27:25-32

35. Akiyama K, Chen C, Wang D, Xu X, Qu C, Yamaza T, et al. Mesenchymal-stemcell-induced immunoregulation involves FAS-ligand-/FAS-mediated $T$ cell apoptosis. Cell Stem Cell. 2012;10:544-55.

36. Shi Y, Wang Y, Li Q, Liu K, Hou J, Shao C, et al. Immunoregulatory mechanisms of mesenchymal stem and stromal cells in inflammatory diseases. Nat. Rev. Nephrol. 2018;14:493-507.

37. Acquistapace A, Bru T, Lesault PF, Figeac F, Coudert AE, le Coz O, et al. Human mesenchymal stem cells reprogram adult cardiomyocytes toward a progenitorlike state through partial cell fusion and mitochondria transfer. Stem Cells. 2011;29:812-24.

38. Ahmad T, Mukherjee S, Pattnaik B, Kumar M, Singh S, Rehman R, et al. Miro1 regulates intercellular mitochondrial transport \& enhances mesenchymal stem cell rescue efficacy. EMBO J. 2014;33:994-1010.

39. Paliwal S, Chaudhuri R, Agrawal A, Mohanty S. Regenerative abilities of mesenchymal stem cells through mitochondrial transfer. J. Biomed. Sci. 2018;25:31.

40. Luz-Crawford P, Hernandez J, Djouad F, Luque-Campos N, Caicedo A, CarrereKremer S, et al. Mesenchymal stem cell repression of Th17 cells is triggered by mitochondrial transfer. Stem Cell Res. Ther. 2019;10:232.

41. Gao J, Qin A, Liu D, Ruan R, Wang Q, Yuan J, et al. Endoplasmic reticulum mediates mitochondrial transfer within the osteocyte dendritic network. Sci. Adv. 2019;5:eaaw7215.

42. Xu LL, Liu YM, Sun YX, Wang B, Xiong YP, Lin WP, et al. Tissue source determines the differentiation potentials of mesenchymal stem cells: a comparative study of human mesenchymal stem cells from bone marrow and adipose tissue. Stem Cell Res. Ther. 2017;8:1-11.

43. Katsuda T, Ochiya T. Molecular signatures of mesenchymal stem cell-derived extracellular vesicle-mediated tissue repair. Stem Cell Res. Ther. 2015;6:212.

44. Wang ZG, He ZY, Liang S, Yang Q, Cheng P, Chen AM. Comprehensive proteomic analysis of exosomes derived from human bone marrow, adipose tissue, and umbilical cord mesenchymal stem cells. Stem Cell Res. Ther. 2020;11:511.

45. Wanet A, Caruso M, Domelevo Entfellner JB, Najar M, Fattaccioli A, Demazy C, et al. The transcription factor 7-like 2-peroxisome proliferator-activated receptor gamma coactivator-1 alpha axis connects mitochondrial biogenesis and metabolic shift with stem cell commitment to hepatic differentiation. Stem Cells. 2017:35:2184-97.

46. Paliwal S, Chaudhuri R, Agrawal A, Mohanty S. Human tissue-specific MSCS demonstrate differential mitochondria transfer abilities that may determine their regenerative abilities. Stem Cell Res. Ther. 2018;9:298.

47. Chiu RW, Chan LY, Lam NY, Tsui NB, Ng EK, Rainer TH, et al. Quantitative analysis of circulating mitochondrial DNA in plasma. Clin. Chem. 2003;49:719-26.

48. Al Amir Dache Z, Otandault A, Tanos R, Pastor B, Meddeb R, Sanchez C, et al. Blood contains circulating cell-free respiratory competent mitochondria. FASEB J. 2020;34:3616-30.

49. Nombela-Arrieta C, Ritz J, Silberstein LE. The elusive nature and function of mesenchymal stem cells. Nat. Rev. Mol. Cell Biol. 2011;12:126-31.

50. Parker DJ, lyer $A$, Shah $S$, Moran A, Hjelmeland AB, Basu MK, et al. A new mitochondrial pool of cyclin $E$, regulated by Drp1, is linked to cell-densitydependent cell proliferation. J. Cell Sci. 2015;128:4171-82.
51. St John JC, Facucho-Oliveira J, Jiang Y, Kelly R, Salah R. Mitochondrial DNA transmission, replication and inheritance: a journey from the gamete through the embryo and into offspring and embryonic stem cells. Hum. Reprod. Update. 2010;16:488-509.

52. Kelly RD, Rodda AE, Dickinson A, Mahmud A, Nefzger CM, Lee W, et al. Mitochondrial DNA haplotypes define gene expression patterns in pluripotent and differentiating embryonic stem cells. Stem Cells. 2013;31:703-16.

53. Lin W, Xu L, Li G. A novel protocol for isolation and culture of multipotent progenitor cells from human urine. J. Orthop. Transl. 2019;19:12-7.

54. Wilson A, Hodgson-Garms M, Frith JE, Genever P. Multiplicity of mesenchymal stromal cells: finding the right route to therapy. Front Immunol. 2019;10:1112.

55. Morita $\mathrm{Y}$, Ema H, Nakauchi $\mathrm{H}$. Heterogeneity and hierarchy within the most primitive hematopoietic stem cell compartment. J. Exp. Med. 2010;207: 1173-82.

56. Ban-Ishihara R, Ishihara T, Sasaki N, Mihara K, Ishihara N. Dynamics of nucleoid structure regulated by mitochondrial fission contributes to cristae reformation and release of cytochrome c. Proc. Natl Acad. Sci. USA. 2013;110:11863-8.

57. Friedman JR, Lackner LL, West M, DiBenedetto JR, Nunnari J, Voeltz GK. ER tubules mark sites of mitochondrial division. Science 2011;334:358-62.

58. Lewis SC, Uchiyama LF, Nunnari J. ER-mitochondria contacts couple mtDNA synthesis with mitochondrial division in human cells. Science. 2016;353:aaf5549.

59. Gherghiceanu M, Popescu LM. Cardiomyocyte precursors and telocytes in epicardial stem cell niche: electron microscope images. J. Cell Mol. Med. 2010;14:871-7.

60. Russell KC, Phinney DG, Lacey MR, Barrilleaux BL, Meyertholen KE, O'Connor KC. In vitro high-capacity assay to quantify the clonal heterogeneity in trilineage potential of mesenchymal stem cells reveals a complex hierarchy of lineage commitment. Stem Cells. 2010;28:788-98.

61. Godwin S, Ward D, Pedone E, Homer M, Fletcher AG, Marucci L. An extended model for culture-dependent heterogenous gene expression and proliferation dynamics in mouse embryonic stem cells. NPJ Syst. Biol. Appl. 2017;3:19.

62. Rennert RC, Januszyk M, Sorkin M, Rodrigues M, Maan ZN, Duscher D, et al. Microfluidic single-cell transcriptional analysis rationally identifies novel surface marker profiles to enhance cell-based therapies. Nat. Commun. 2016;7:11945.

63. Bigarella $\mathrm{CL}$, Liang R, Ghaffari S. Stem cells and the impact of ROS signaling. Development 2014;141:4206-18.

64. Zon LI. Intrinsic and extrinsic control of haematopoietic stem-cell self-renewal. Nature 2008;453:306-13.

65. Lisowski P, Kannan P, Mlody B, Prigione A. Mitochondria and the dynamic control of stem cell homeostasis. EMBO Rep. 2018;19:e45432.

66. Campello S, Scorrano L. Mitochondrial shape changes: orchestrating cell pathophysiology. EMBO Rep. 2010;11:678-84.

67. Bahat A, Gross A. Mitochondrial plasticity in cell fate regulation. J. Biol. Chem. 2019;294:13852-63.

68. Maryanovich M, Zaltsman $Y$, Ruggiero A, Goldman A, Shachnai L, Zaidman SL, et al. An $\mathrm{MTCH} 2$ pathway repressing mitochondria metabolism regulates haematopoietic stem cell fate. Nat. Commun. 2015;6:7901.

69. Anso E, Weinberg SE, Diebold LP, Thompson BJ, Malinge S, Schumacker PT, et al. The mitochondrial respiratory chain is essential for haematopoietic stem cell function. Nat. Cell Biol. 2017;19:614-25.

70. Hinge A, He J, Bartram J, Javier J, Xu J, Fjellman E, et al. Asymmetrically segregated mitochondria provide cellular memory of hematopoietic stem cell replicative history and drive HSC attrition. Cell Stem Cell. 2020;26:420-30 e6.

71. Chung JY, Steen JA, Schwarz TL. Phosphorylation-induced motor shedding is required at mitosis for proper distribution and passive inheritance of mitochondria. Cell Rep. 2016;16:2142-55.

72. Katajisto $\mathrm{P}$, Dohla J, Chaffer CL, Pentinmikko N, Marjanovic N, lqbal S, et al. Stem cells. Asymmetric apportioning of aged mitochondria between daughter cells is required for stemness. Science. 2015;348:340-3.

73. Yamashita YM, Mahowald AP, Perlin JR, Fuller MT. Asymmetric inheritance of mother versus daughter centrosome in stem cell division. Science. 2007:315:518-21.

74. Mohrin M, Shin J, Liu Y, Brown K, Luo H, Xi Y, et al. Stem cell aging. A mitochondrial UPR-mediated metabolic checkpoint regulates hematopoietic stem cell aging. Science. 2015;347:1374-7.

75. Iwata $R$, Casimir P, Vanderhaeghen P. Mitochondrial dynamics in postmitotic cells regulate neurogenesis. Science. 2020;369:858-62.

76. Ren L, Chen X, Chen X, Li J, Cheng B, Xia J. Mitochondrial dynamics: fission and fusion in fate determination of mesenchymal stem cells. Front Cell Dev. Biol. 2020;8:580070.

77. Agathocleous M, Love NK, Randlett O, Harris JJ, Liu J, Murray AJ, et al. Metabolic differentiation in the embryonic retina. Nat. Cell Biol. 2012;14:859-64.

78. Chen CT, Shih YRV, Kuo TK, Lee OK, Wei YH. Coordinated changes of mitochondrial biogenesis and antioxidant enzymes during osteogenic differentiation of human mesenchymal stem cells. Stem Cells. 2008;26:960-8. 
79. Chung S, Dzeja PP, Faustino RS, Perez-Terzic C, Behfar A, Terzic A. Mitochondrial oxidative metabolism is required for the cardiac differentiation of stem cells. Nat. Clin. Pract. Cardiovascular Med. 2007;4:S60-S7.

80. Folmes CD, Dzeja PP, Nelson TJ, Terzic A. Metabolic plasticity in stem cell homeostasis and differentiation. Cell Stem Cell. 2012;11:596-606.

81. Mandal S, Lindgren AG, Srivastava AS, Clark AT, Banerjee U. Mitochondrial function controls proliferation and early differentiation potential of embryonic stem cells. Stem Cells. 2011;29:486-95.

82. Khacho M, Clark A, Svoboda DS, Azzi J, MacLaurin JG, Meghaizel C, et al. Mitochondrial dynamics impacts stem cell identity and fate decisions by regulating a nuclear transcriptional program. Cell Stem Cell. 2016;19:232-47.

83. Hoque A, Sivakumaran P, Bond ST, Ling NXY, Kong AM, Scott JW, et al. Mitochondrial fission protein Drp1 inhibition promotes cardiac mesodermal differentiation of human pluripotent stem cells. Cell Death Discov. 2018;4:39.

84. Xu Y, Zhang Y, Garcia-Canaveras JC, Guo L, Kan M, Yu S, et al. Chaperonemediated autophagy regulates the pluripotency of embryonic stem cells. Science. 2020;369:397-403.

85. TeSlaa T, Chaikovsky AC, Lipchina I, Escobar SL, Hochedlinger K, Huang J, et al. alpha-Ketoglutarate accelerates the initial differentiation of primed human pluripotent stem cells. Cell Metab. 2016;24:485-93.

86. Lu V, Dahan P, Ahsan FM, Patananan AN, Roy IJ, Torres A Jr, et al. Mitochondrial metabolism and glutamine are essential for mesoderm differentiation of human pluripotent stem cells. Cell Res. 2019;29:596-8.

87. Schieke SM, Ma M, Cao L, McCoy JP Jr, Liu C, Hensel NF, et al. Mitochondrial metabolism modulates differentiation and teratoma formation capacity in mouse embryonic stem cells. J. Biol. Chem. 2008;283:28506-12.

88. Ma MS, Kannan V, de Vries AE, Czepiel M, Wesseling EM, Balasubramaniyan V, et al. Characterization and comparison of osteoblasts derived from mouse embryonic stem cells and induced pluripotent stem cells. J. Bone Min. Metab. 2017;35:21-30.

89. Daw CC, Ramachandran K, Enslow BT, Maity S, Bursic B, Novello MJ, et al. Lactate elicits ER-mitochondrial $\mathrm{Mg}(2+)$ dynamics to integrate cellular metabolism. Cell. 2020;183:474-89 e17.

90. Alt EU, Senst C, Murthy SN, Slakey DP, Dupin CL, Chaffin AE, et al. Aging alters tissue resident mesenchymal stem cell properties. Stem Cell Res. 2012;8:215-25.

91. Berger E, Rath E, Yuan D, Waldschmitt N, Khaloian S, Allgauer M, et al. Mitochondrial function controls intestinal epithelial stemness and proliferation. Nat. Commun. 2016;7:13171.

92. Zong Z, Zhang X, Yang Z, Yuan W, Huang J, Lin W, et al. Rejuvenated ageing mesenchymal stem cells by stepwise preconditioning ameliorates surgeryinduced osteoarthritis in rabbits. Bone Jt. Res. 2021;10:10-21.

93. Chakkalakal JV, Jones KM, Basson MA, Brack AS. The aged niche disrupts muscle stem cell quiescence. Nature. 2012;490:355-60.

94. Maryanovich $M$, Zahalka AH, Pierce $H$, Pinho S, Nakahara F, Asada $N$, et al. Adrenergic nerve degeneration in bone marrow drives aging of the hematopoietic stem cell niche. Nat. Med. 2018;24:782-91.

95. Lopez-Otin C, Blasco MA, Partridge L, Serrano M, Kroemer G. The hallmarks of aging. Cell. 2013;53:1194-217.

96. Oh J, Lee YD, Wagers AJ. Stem cell aging: mechanisms, regulators and therapeutic opportunities. Nat. Med. 2014;20:870-80.

97. Baker N, Boyette LB, Tuan RS. Characterization of bone marrow-derived mesenchymal stem cells in aging. Bone 2015;70:37-47.

98. Chen $C$, Liu Y, Liu R, Ikenoue T, Guan KL, Zheng P. TSC-mTOR maintains quiescence and function of hematopoietic stem cells by repressing mitochondrial biogenesis and reactive oxygen species. J. Exp. Med. 2008;205: 2397-408

99. Jaiswal S, Fontanillas P, Flannick J, Manning A, Grauman PV, Mar BG, et al. Agerelated clonal hematopoiesis associated with adverse outcomes. N. Engl. J. Med. 2014;371:2488-98.

100. Shyh-Chang N, Daley GQ, Cantley LC. Stem cell metabolism in tissue development and aging. Development 2013;140:2535-47.

101. Vannini N, Girotra M, Naveiras O, Nikitin G, Campos V, Giger S, et al. Specification of haematopoietic stem cell fate via modulation of mitochondrial activity. Nat. Commun. 2016;7:13125.

102. Zhang $H$, Ryu D, Wu Y, Gariani $K$, Wang $X$, Luan $P$, et al. NAD(+) repletion improves mitochondrial and stem cell function and enhances life span in mice. Science. 2016;352:1436-43.

103. Jin C, Li J, Green CD, Yu X, Tang X, Han D, et al. Histone demethylase UTX-1 regulates $C$. elegans life span by targeting the insulin/IGF-1 signaling pathway. Cell Metab. 2011;14:161-72.

104. Brown K, Xie S, Qiu X, Mohrin M, Shin J, Liu Y, et al. SIRT3 reverses aging associated degeneration. Cell Rep. 2013;3:319-27.

105. Ito K, Turcotte R, Cui J, Zimmerman SE, Pinho S, Mizoguchi T, et al. Self-renewal of a purified Tie2+ hematopoietic stem cell population relies on mitochondrial clearance. Science. 2016;354:1156-60.
106. Chen Z, Amro EM, Becker F, Holzer M, Rasa SMM, Njeru SN, et al. Cohesinmediated NF-kappaB signaling limits hematopoietic stem cell self-renewal in aging and inflammation. J. Exp. Med. 2019;216:152-75.

107. Youm YH, Grant RW, McCabe LR, Albarado DC, Nguyen KY, Ravussin A, et al. Canonical Nlrp3 inflammasome links systemic low-grade inflammation to functional decline in aging. Cell Metab. 2013;18:519-32.

108. Youm YH, Kanneganti TD, Vandanmagsar B, Zhu X, Ravussin A, Adijiang A, et al. The Nlrp3 inflammasome promotes age-related thymic demise and immunosenescence. Cell Rep. 2012;1:56-68.

109. Luo H, Mu WC, Karki R, Chiang HH, Mohrin M, Shin JJ, et al. Mitochondrial stressinitiated aberrant activation of the NLRP3 inflammasome regulates the functional deterioration of hematopoietic stem cell aging. Cell Rep. 2019;26:945-54 e4.

110. Yu WM, Liu X, Shen J, Jovanovic O, Pohl EE, Gerson SL, et al. Metabolic regulation by the mitochondrial phosphatase PTPMT1 is required for hematopoietic stem cell differentiation. Cell Stem Cell. 2013;12:62-74.

111. Tsang KY, Chan D, Cheslett D, Chan WC, So CL, Melhado IG, et al. Surviving endoplasmic reticulum stress is coupled to altered chondrocyte differentiation and function. PLoS Biol. 2007;5:e44.

112. Hetz $C$. The unfolded protein response: controlling cell fate decisions under ER stress and beyond. Nat. Rev. Mol. Cell Biol. 2012;13:89-102.

113. Kourtis N, Tavernarakis N. Cellular stress response pathways and ageing: intricate molecular relationships. EMBO J. 2011;30:2520-31.

114. Haigis MC, Yankner BA. The aging stress response. Mol. Cell. 2010;40:333-44.

115. Taormina G, Ferrante F, Vieni S, Grassi N, Russo A, Mirisola MG. Longevity: lesson from model organisms. Genes (Basel). 2019;10:518.

116. Liu L, Zhao M, Jin X, Ney G, Yang KB, Peng F, et al. Adaptive endoplasmic reticulum stress signalling via IRE1alpha-XBP1 preserves self-renewal of haematopoietic and pre-leukaemic stem cells. Nat. Cell Biol. 2019;21:328-37.

117. Bravo R, Gutierrez T, Paredes F, Gatica D, Rodriguez AE, Pedrozo Z, et al Endoplasmic reticulum: ER stress regulates mitochondrial bioenergetics. Int. J. Biochem. Cell Biol. 2012:44:16-20.

118. Chan WCW, Tsang KY, Cheng YW, Ng VCW, Chik H, Tan ZJ, et al. Activating the unfolded protein response in osteocytes causes hyperostosis consistent with craniodiaphyseal dysplasia. Hum. Mol. Genet. 2017;26:4572-87.

119. Abdullahi A, Barayan D, Vinaik R, Diao L, Yu N, Jeschke MG. Activation of ER stress signalling increases mortality after a major trauma. J. Cell Mol. Med. 2020;24:9764-73.

120. Ricci D, Marrocco I, Blumenthal D, Dibos M, Eletto D, Vargas J, et al. Clustering of IRE1alpha depends on sensing ER stress but not on its RNase activity. FASEB J. 2019:33:9811-27.

121. Bravo-Sagua R, Parra V, Ortiz-Sandoval C, Navarro-Marquez $M$, Rodriguez $A E$, Diaz-Valdivia N, et al. Caveolin-1 impairs PKA-DRP1-mediated remodelling of ERmitochondria communication during the early phase of ER stress. Cell Death Differ. 2019;26:1195-212.

122. Hamasaki M, Furuta N, Matsuda A, Nezu A, Yamamoto A, Fujita N, et al. Autop hagosomes form at ER-mitochondria contact sites. Nature. 2013:495:389-93.

123. Cortez $\mathrm{L}, \operatorname{Sim} \mathrm{V}$. The therapeutic potential of chemical chaperones in protein folding diseases. Prion 2014;8:97-202.

124. Friedman JR, Webster BM, Mastronarde DN, Verhey KJ, Voeltz GK. ER sliding dynamics and ER-mitochondrial contacts occur on acetylated microtubules. J. Cell Biol. 2010;190:363-75.

125. English AM, Schuler MH, Xiao T, Kornmann B, Shaw JM, Hughes AL. ERmitochondria contacts promote mitochondrial-derived compartment biogenesis. J. Cell Biol. 2020;219:e202002144.

126. Goodrum JM, Lever AR, Coody TK, Gottschling DE, Hughes ALRsp5. and Mdm30 reshape the mitochondrial network in response to age-induced vacuole stress. Mol. Biol. Cell. 2019;30:2141-54.

127. Schuler M-H, English AM, Campbell TJ, Shaw JM, Hughes AL. Mitochondrialderived compartments facilitate cellular adaptation to amino acid stress. [Preprint]. 2020. Available from https://doi.org/10.1101/2020.03.13.991091.

128. Chen Q, Samidurai A, Thompson J, Hu Y, Das A, Willard B, et al. Endoplasmic reticulum stress-mediated mitochondrial dysfunction in aged hearts. Biochim. Biophys. Acta Mol. Basis Dis. 2020;1866:165899.

129. Bravo R, Vicencio JM, Parra V, Troncoso R, Munoz JP, Bui M, et al. Increased ERmitochondrial coupling promotes mitochondrial respiration and bioenergetics during early phases of ER stress. J. Cell Sci. 2011;124:2143-52.

130. Glancy B, Balaban RS. Role of mitochondrial $\mathrm{Ca} 2+$ in the regulation of cellular energetics. Biochemistry 2012;51:2959-73.

131. Honrath B, Metz I, Bendridi N, Rieusset J, Culmsee C, Dolga AM. Glucoseregulated protein 75 determines ER-mitochondrial coupling and sensitivity to oxidative stress in neuronal cells. Cell Death Discov. 2017:3:17076.

132. Liu X, Hajnoczky G. Ca2+-dependent regulation of mitochondrial dynamics by the Miro-Milton complex. Int. J. Biochem. Cell Biol. 2009;41:1972-6.

133. Knupp J, Arvan $P$, Chang A. Increased mitochondrial respiration promotes survival from endoplasmic reticulum stress. Cell Death Differ. 2019;26:487-501. 
134. Mironov SL, Ivannikov MV, Johansson M. [Ca2+]i signaling between mitochondria and endoplasmic reticulum in neurons is regulated by microtubules. From mitochondrial permeability transition pore to $\mathrm{Ca} 2+-$ induced $\mathrm{Ca} 2+$ release. J. Biol. Chem. 2005;280:715-21.

135. Shan X, Roberts C, Lan Y, Percec I. Age alters chromatin structure and expression of SUMO proteins under stress conditions in human adipose-derived stem cells. Sci. Rep. 2018;8:11502.

136. Liu H, Huang B, Xue S, U KP, Tsang LL, Zhang X, et al. Functional crosstalk

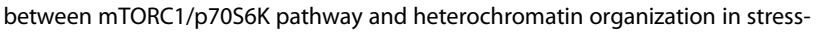
induced senescence of MSCs. Stem Cell Res. Ther. 2020;11:279.

137. Zhu D, Wu X, Zhou J, Li X, Huang X, Li J, et al. NuRD mediates mitochondrial stress-induced longevity via chromatin remodeling in response to acetyl-CoA level. Sci. Adv. 2020;6:eabb2529.

138. Pietrangelo L, D'Incecco A, Ainbinder A, Michelucci A, Kern H, Dirksen RT, et al. Age-dependent uncoupling of mitochondria from $\mathrm{Ca2}(+)$ release units in skeletal muscle. Oncotarget. 2015;6:35358-71.

139. Miyamoto K, Tajima Y, Yoshida K, Oikawa M, Azuma R, Allen GE, et al. Reprogramming towards totipotency is greatly facilitated by synergistic effects of small molecules. Biol. Open. 2017;6:415-24.

140. Oliverio S, Beltran JSO, Occhigrossi L, Bordoni V, Agrati C, D'Eletto M, et al. Transglutaminase type 2 is involved in the hematopoietic stem cells homeostasis. Biochemistry. 2020;85:1159-68.

141. Cakouros D, Gronthos S. The changing epigenetic landscape of mesenchymal stem/stromal cells during aging. Bone 2020;137:115440.

142. Betto RM, Diamante L, Perrera V, Audano M, Rapelli S, Lauria A, et al. Metabolic control of DNA methylation in naive pluripotent cells. Nat. Genet. 2021;53:215-29.

143. Terasaki M, Chen LB, Fujiwara K. Microtubules and the endoplasmic reticulum are highly interdependent structures. J. Cell Biol. 1986;103:1557-68.

144. Choi GE, Oh JY, Lee HJ, Chae CW, Kim JS, Jung YH, et al. Glucocorticoid-mediated ER-mitochondria contacts reduce AMPA receptor and mitochondria trafficking into cell terminus via microtubule destabilization. Cell Death Dis. 2018;9:1137.

145. Liu X, Zhang Y, Ni M, Cao H, Signer RAJ, Li D, et al. Regulation of mitochondrial biogenesis in erythropoiesis by mTORC1-mediated protein translation. Nat. Cell Biol. 2017;19:626-38.

\section{ACKNOWLEDGEMENTS}

Figure $2 \mathrm{~B}$ was adapted from netterimages.com and chegg.com. Figure 3 and 4 were created through content and elements of BioRender.com (2021) with a granted license (https://app.biorender.com/biorender-templates)

\section{AUTHOR CONTRIBUTIONS}

G.L., X.J., and W.Y.-W.L.: conceptualization, framework design, manuscript editing, and funding support. W.L., S.C., Y.W., and M.W.: collection of relevant literature and research data, manuscript writing, and figure preparation. All authors contributed to substantial discussion of content and approval of the final version.

\section{FUNDING}

This work was funded by Hong Kong Government Research Grants Council, Collaborative Research Fund (C7030-18G to G.L.), General Research Fund (19-093GRF, 14120118, 9054014, N_CityU102/15, and 14119115 to G.L.), Hong Kong Innovation Technology Commission Funds (PRP/050/19FX and ITS/448/18 to G.L. and X.J.), Natural Science Foundation of Guang Dong (2018B030311065 to X.J.), National Natural Science Foundation of China (NSFC No. 31970815 to X.J.), Hong Kong UGC/GRF (14165217 to X.J.), Start-up Fund of The Chinese University of Hong Kong, Hong Kong SAR (Reference number 4930991 to W.Y.-W.L.). This study was also supported by the research funds from Health@InnoHK Program launched by Innovation Technology Commission of the Hong Kong SAR, P. R. China, and Sports Medicine and Regenerative Technology Program, Lui Che Woo Institute of Innovative Medicine, The Chinese University of Hong Kong.

\section{ETHICS STATEMENT}

Not applicable.

\section{COMPETING INTERESTS}

The authors declare no competing interests.

\section{ADDITIONAL INFORMATION}

Correspondence and requests for materials should be addressed to W.L. or G.L.

Reprints and permission information is available at http://www.nature.com/ reprints

Publisher's note Springer Nature remains neutral with regard to jurisdictional claims in published maps and institutional affiliations.

(i) Open Access This article is licensed under a Creative Commons Attribution 4.0 International License, which permits use, sharing, adaptation, distribution and reproduction in any medium or format, as long as you give appropriate credit to the original author(s) and the source, provide a link to the Creative Commons license, and indicate if changes were made. The images or other third party material in this article are included in the article's Creative Commons license, unless indicated otherwise in a credit line to the material. If material is not included in the article's Creative Commons license and your intended use is not permitted by statutory regulation or exceeds the permitted use, you will need to obtain permission directly from the copyright holder. To view a copy of this license, visit http://creativecommons. org/licenses/by/4.0/.

(c) The Author(s) 2021 